NOTE

\title{
Seminoma in a koi carp Cyprinus carpio: histopathological and immunohistochemical findings
}

\author{
Rubina Sirri ${ }^{1, *}$, Luciana Mandrioli ${ }^{1}$, Valeria Grieco ${ }^{2}$, Barbara Bacci ${ }^{1}$, \\ Barbara Brunetti ${ }^{1}$, Giuseppe Sarli ${ }^{1}$, Heike Schmidt-Posthaus ${ }^{3}$
}

\begin{abstract}
${ }^{1}$ Servizio di Prova di Anatomia Patologica, Dipartimento di Sanità Pubblica Veterinaria e Patologia Animale, Facoltà di Medicina Veterinaria, Alma Mater Studiorum Università di Bologna, Via Tolara di Sopra 50, 40064 Ozzano Emilia (BO), Italy

${ }^{2}$ Dipartimento di Patologia Animale, Igiene e Sanità Pubblica Veterinaria, Sezione di Anatomia Patologica Veterinaria e Patologia Aviare, Facoltà di Medicina Veterinaria, Università degli Studi di Milano, Via Celoria 10, 20133 Milan, Italy

${ }^{3}$ Centre for Fish and Wildlife Health, Institute of Animal Pathology, University of Bern, Laenggassstrasse 122, 3012 Bern, Switzerland
\end{abstract}

\begin{abstract}
A spontaneous seminoma in a 3 yr old male koi carp Cyprinus carpio L. is described. The animal, presenting a symmetric abdominal enlargement, showed a celomatic multinodular, whiteyellowish and firm mass that infiltrated the liver and the intestine wall. Histologically, the neoplasm was non-encapsulated and poorly demarcated, showed invasive growth and was characterized by a lobular architecture, subdivided by abundant fibro-connective septa. Large necrotic and calcified areas together with small aggregates of residual spermatids were present. We diagnosed a classical seminoma with a diffuse pattern. Neoplastic cells cross-reacted with vimentin, placental alkaline phosphatase, and c-KIT. An immunohistochemical phenotypization of the tumor was performed to exclude other celomatic neoplasms and to compare this seminoma with those reported in mammals and humans.
\end{abstract}

KEY WORDS: Seminoma $\cdot$ Koi carp $\cdot$ Histology $\cdot$ Immunohistochemistry

\section{INTRODUCTION}

Gonadal neoplasms are generally considered to be rare in fishes (Hawkins et al. 1996, Groff 2004). Spontaneous testicular tumors of gonadic germ cells (spermatogonia) have been identified in zebrafish Danio rerio Hamilton (Smolowitz et al. 2002, Spitsbergen \& Kent 2003), barbel Barbus barbus L. (Palikova et al. 2007), African lungfish species Protopterus aethiopicus Heckel, P. dolloi Boulenger, P. annectens Owen (Nigrelli \& Jakowska 1953, Masahito et al. 1984, Hubbard \& Fletcher 1985), black seabass Centropristis striata L. (Weisse et al. 2002), yellow perch Perca flavescens Mitchill (Blazer 2002), carp Cyprinus carpio
L., and goldfish Carassius auratus L. (Leatherland \& Sonstegard 1978, Granado-Lorencio et al. 1987, Down \& Leatherland 1989). Spontaneous gonadal stroma tumors such as Sertoli-Leydig cell tumors have been described only in cyprinids (Leatherland \& Sonstegard 1978, Granado-Lorencio et al. 1987, Down \& Leatherland 1989, Groff 2004). Mesenchymal gonadal tumors such as leiomyomas and fibroleiomyomas are common in the testis of yellow perch Perca flavescens Mitchill (Budd et al. 1975, Blazer 2002), in largemouth bass Micropterus salmoides Lacepède (Herman \& Landolt 1975), and in cyprinids (Granado-Lorencio et al. 1987). This is the first report of a spontaneously occurring seminoma in an adult male koi carp Cyprinus carpio L. 
The tumor is described histopathologically, and an immunohistochemical phenotypization was performed to exclude other celomatic neoplasms such as hepatic or intestinal carcinoma and lymphoma and to study similarities with mammalian and human seminoma.

\section{MATERIALS AND METHODS}

A 3 yr old male koi carp Cyprinus carpio L. with gross pathological symptoms consisting of a symmetrical abdominal enlargement was examined histologically and immunohistochemically. The first $2 \mathrm{yr}$, the fish was kept in a farm with natural reproduction in Italy. It was then kept for 1 yr with other koi carp in a pet shop tank, during which period it was not treated with chemicals.

Immediately after death, the animal was sent to the Servizio di Anatomia Patologica, Deparment of Veterinary Public Health and Animal Pathology, Faculty of Veterinary, Bologna, Italy, for further investigation. A complete necropsy was performed, and parts of the neoplastic mass and liver, intestine, swim bladder, kidney, gills, skin, and muscle were removed and fixed in $10 \%$ formalin or Bouin's fixative for histological examination. Sections were stained with hematoxylin and eosin (H\&E). Additional samples of the mass were stained with periodic acid-Schiff (PAS) to detect the presence of glycogen in gonocytes. For immunohistochemistry, only formalin-fixed tissue samples from the mass were used. Immunohistochemistry was performed with antibodies against cytokeratin (1:50, clone AE1/AE3; Dako), vimentin (prediluted, clone V9; Novocastra), c-KIT (1:600, polyclonal; Dako), placental alkaline phosphatase (PLAP) (1:25, clone 8A9; Dako), alpha-fetoprotein (AFP) (prediluted, clone C3; BioGenex Laboratories), estrogen receptor (ER) (prediluted, clone SP1; Ventana Medical Systems), neuronspecific enolase (NSE) (1:1600, clone AB-1; NeoMarkers), calretinin (1:100, clone AB-1; NeoMarkers), CD3 (1:75, clone F7.2.38; Dako), CD79 $\alpha$ (1:10, clone HM57; Dako), CD45RA (1:20, clone 4KB5; Dako). A mammal positive control and a non-diseased carp testis were added. For negative control purposes, the primary antibody was replaced by a monoclonal antibody of irrelevant specificity (mouse anti-IgG1, DAKO X0931; Dako).

Briefly, endogenous peroxidase activity was blocked. Tissue sections were treated for antigen retrieval in citrate buffer at $\mathrm{pH} 6.0$ or EDTA buffer at $\mathrm{pH}$ 9.0, according to the manufacturer's instructions. The sections were incubated with the primary antibody. A manual staining protocol was employed for cytokeratin AE1/AE3, PLAP, CD3, CD79 $\alpha$ and CD45RA; an automated staining system (BenchMark ${ }^{\circledR}$
Ventana Medical Systems; Bond ${ }^{\mathrm{TM}}$ maX Menarini) was used for AFP, NSE, c-KIT, calretinin, vimentin, and ER. The revealing system used was the $\mathrm{LSAB}^{\circledR}$ kit (Dako) for cytokeratin AE1/AE3, PLAP, CD3, CD79 $\alpha$, CD45RA, and the EnVision ${ }^{\mathrm{TM}}$ System (Dako) for ER, AFP, NSE, c-KIT, calretinin, and vimentin. Antibody localization was subsequently visualized using 3,3'diaminobenzidine (DAB) (Sigma Chemical) and counterstaining with Papanicolau hematoxylin.

\section{RESULTS}

Clinically, the animal showed lethargy for a duration of $1 \mathrm{mo}$. One wk before death, the animal presented signs of anorexia and marked abdominal enlargement. The skin overlaying the enlargement was thinned and scales were missing.

At necropsy, a multinodular, $7 \times 5 \times 3.5 \mathrm{~cm}$, white-yellowish and firm mass filling the celomatic cavity was detected. The mass was located ventral to the kidney and to the swim bladder. It appeared non-encapsulated, and its anterior portion showed a bosselated pattern that had infiltrated and replaced a large area of the liver lobes. The intestinal loops were also invaded, making it impossible to unravel them. The kidney, gall bladder, and swim bladder were not invaded by the mass. Gonads were not recognizable (Fig. 1a).

Histologically, the neoplasm was non-encapsulated, poorly demarcated, and it compressed the hepatic parenchyma, causing atrophy. The mass appeared multilobulated and highly cellular, and was character-

Fig. 1. (a) Koi carp Cyprinus carpio L.. Multinodular, whiteyellowish firm mass filling the celomatic cavity. Anterior portion of the mass shows a bossellated pattern that infiltrates and replaces much of the liver lobes. Intestinal loops are also massively invaded and not easily detectable. (b) Seminoma. Lobular architecture of the neoplastic mass subdivided by abundant fibro-connectival septa. Scale bar $=5 \mu \mathrm{m}$. Stain: Hematoxylin and eosin (H\&E). (c) Seminoma. The mass massively infiltrates the hepatic parenchyma (arrows). Note the residual biliary ducts (BD), the hepatic veins (V), and the islets of pancreatic tissue (arrowhead). Scale bar $=10 \mu \mathrm{m}$. Stain: H\&E. (d) Seminoma. Neoplastic lobules infiltrate the intestinal wall (arrow). L: intestinal lumen; M: tunica muscularis. Scale bar $=5 \mu \mathrm{m}$. Stain: H\&E. (e) Seminoma. Neoplastic lobules composed of cellular sheets of poly-gonal cells, supported by fine fibrovascular stroma. Scale bar $=50 \mu \mathrm{m}$. Stain: H\&E. (f) Seminoma. Calcified areas (arrow) and small aggregates of round basophilic cells referred to as residual spermatids $(*)$. Scale bar $=50 \mu \mathrm{m}$. Stain: H\&E. (g) Immunohistochemistry. Neoplastic cells display a focal positive, strong cytoplasmic staining for vimentin. Scale bar $=50 \mu \mathrm{m}$. 3,3'diaminobenzidine (DAB) staining, Papanicolau's hematoxylin counterstain. (h) Immunohistochemistry; neoplastic cells display a focal positive, faint, and cytoplasmic reactivity for placental alkaline phosphatase (PLAP). Scale bar $=50 \mu \mathrm{m}$.

DAB staining, Papanicolau's hematoxylin counterstain 

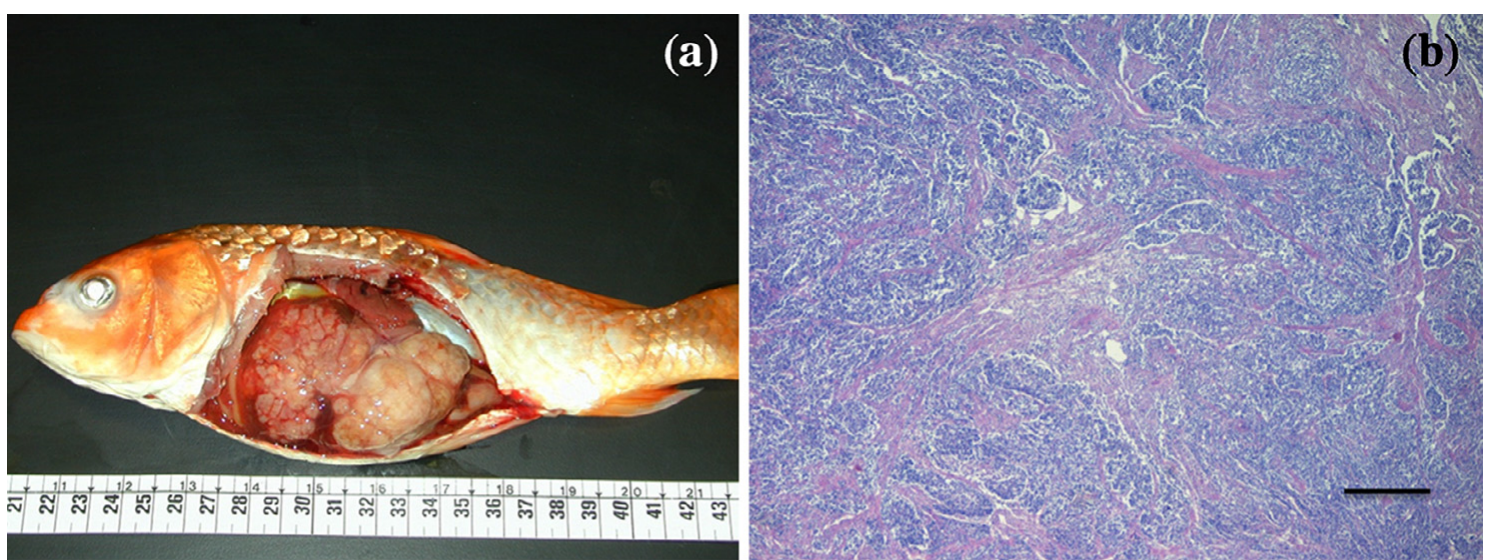

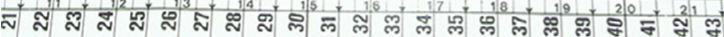
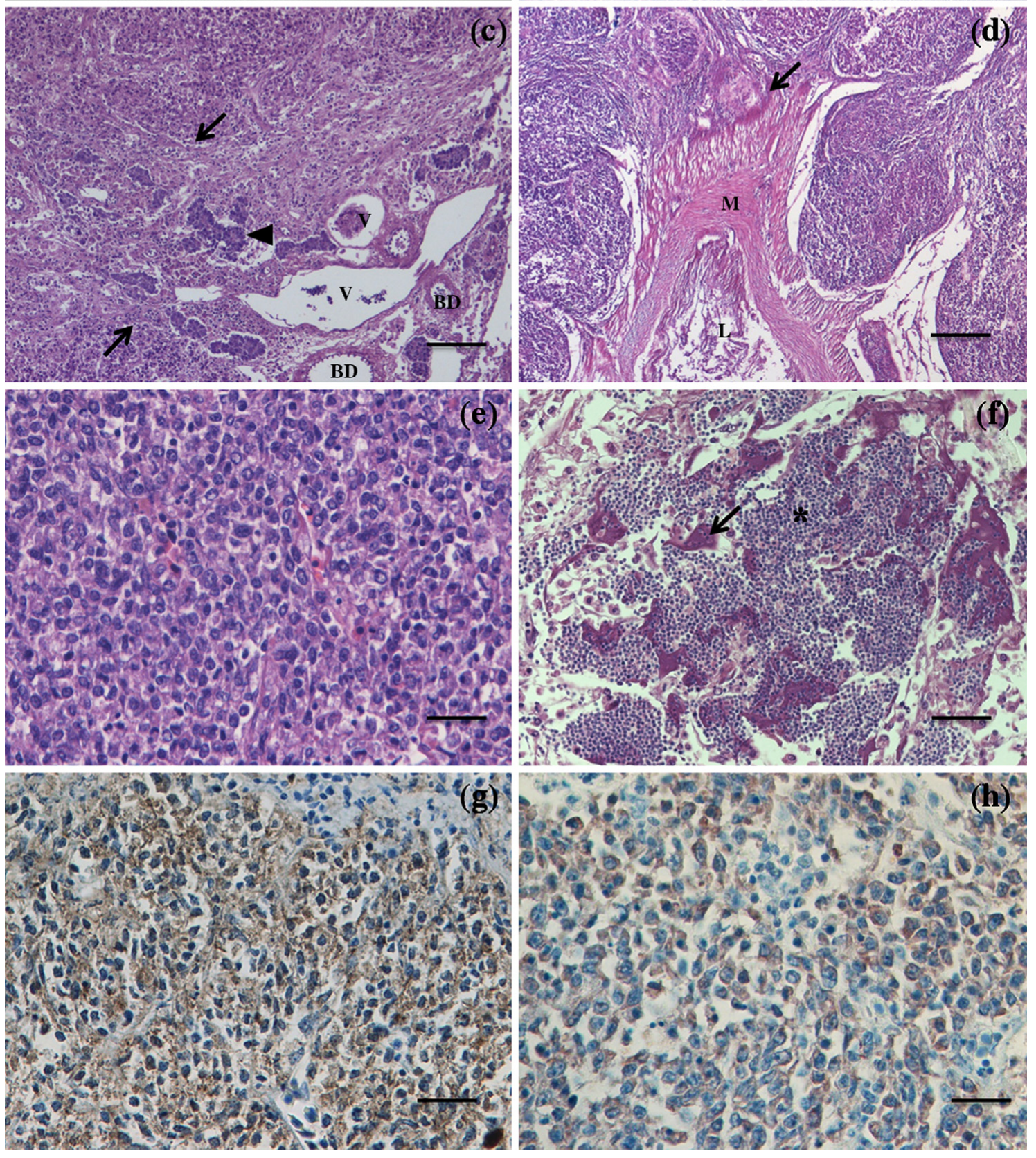

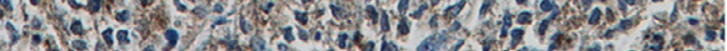
Nosis 0 .

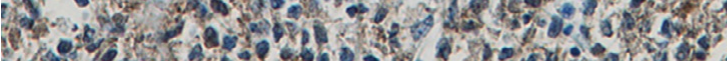

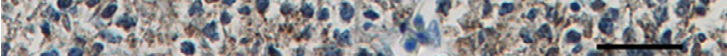

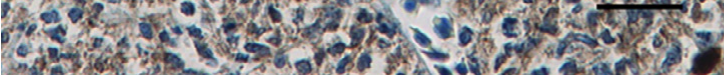


ized by a lobular architecture, subdivided by abundant fibro-connective septa (Fig. 1b). In the stroma, scattered clusters of lymphocytes and melanomacrophages were present. Neoplastic lobules showed an infiltrative growth into the liver, replacing much of the hepatic parenchyma, and into the intestinal wall (Fig. 1c,d).

Lobules were composed of cellular sheets of neoplastic polygonal cells, supported by fine fibrovascular stroma (Fig. 1e). The neoplastic cells were 10 to $15 \mu \mathrm{m}$ in diameter, without well-demarcated cytoplasmic borders. The cytoplasm presented several thin granulations and the nucleus was large, round, hypochromatic, and centrally located, with scattered chromatin and a single nucleolus. There was moderate anisocytosis and anisokaryosis. The mitotic rate was low $(<1$ per high power field). Large necrotic and calcified areas together with small aggregates of 3 to $5 \mu \mathrm{m}$ round basophilic cells consistent with residual spermatids were present (Fig. 1f). Neoplastic cells were PAS-negative.

The neoplastic tissue cross-reacted with vimentin, displaying a focal positive, strong cytoplasmic immunostaining throughout the section (Fig. 1g) and with PLAP showing a focal positive, faint, and cytoplasmic reactivity (Fig. 1h). A mild cytoplasmic focal positive immunoreactivity of neoplastic cells for c-KIT was also present. Fibro-connective septa separating neoplastic lobules showed a cytoplasmic immunoreactivity to cytokeratin AE1/AE3. No positive signal was detected using the antibodies AFP, ER, NSE, calretinin, CD3, CD79 $\alpha$, and CD45RA.

\section{DISCUSSION}

In cyprinids, a high prevalence of spontaneous gonadal neoplasms has been reported in hybrids of goldfish Carassius auratus L. $\times$ common carp Cyprinus carpio L. (Sonstegard 1977, Leatherland \& Sonstegard 1978, Dickman \& Steele 1986, Granado-Lorencio et al. 1987, Down \& Leatherland 1989). The cause of these lesions is uncertain; Sonstegard (1977) hypothesized that this condition was caused by polychlorinated biphenyls or dichloro-diphenyl-trichloroethane, and Dickman \& Steele (1986) attributed them to chemical agents originating from industrial waste. Conversely, Down \& Leatherland (1989) found that these neoplasms were as common in areas relatively free of industrial or heavy domestic discharges as they were in polluted locations. However, a relation to genetic factors has to be considered. In fact, ornamental carp with complex genetic histories also develop ovarian neoplasms that may be hereditary (Ishikawa \& Takayama 1977). The latter authors reported on a wide survey of 21 ovarian neoplasms (dysgerminoma, theca cell tumor, and granulosa cell tumor) in adult nishikigoi hybrid carp C. carpio which occurred from 1974 to 1976, according to data collected by breeders and examination of various previous documents.

Ovarian neoplasms in ornamental koi carp Cyprinus carpio L. are similar to those described in wild goldfish $\times$ carp hybrids: they are common in sexually mature females and apparently originate from the ovary, although the cellular origin is often difficult to determine (Groff 2004). A recent survey of neoplasms in C. carpio L. undertaken by the Centre for Fish and Wildlife Health of Bern, Switzerland, found 44 abdominal tumors, of which 39 were interpreted as gonadal tumors. In accordance with the literature, all animals found with gonadal tumors were females, with the exception of 1 male and 1 hermaphrodite. The neoplasms usually appeared malignant, with invasion of adjacent organs and the presence of poorly differentiated neoplastic cells with a high degree of anisocytosis and anisokaryosis (H. Schmidt-Posthaus \& R. Knüsel unpubl. data). The 2 testicular neoplasms were diagnosed as a sex cord-stromal tumor in a testis and a germ cell tumor in the ovotestis.

To the best of our knowledge, the present study represents the first report of a spontaneously occurring seminoma in an adult male Cyprinus carpio L. Macroscopically, the seminoma was a multinodular, nonencapsulated and firm mass, filling the celomatic cavity and invading the intestinal serosal surface and replacing a large area of the liver lobes. In fact, in cyprinids, the multilobulated liver intertwining between the mesenteries of the intestine may favor the spreading of neoplastic cells by contiguity (Hoole et al. 2001). Gonads were not recognizable, and the neoplastic mass appeared to originate near their normal location. Histologically, the neoplasm was characterized by a lobular pattern subdivided by fibro-connective septa, small aggregates of spermatids, and a low mitotic rate of neoplastic cells. These findings are similar to those described in Japanese medaka Oryzias latipes by Hawkins et al. (1996) and in zebrafish Danio rerio by Smolowitz et al. (2002). Another similarity was the presence of scattered clusters of lymphocytes and melanomacrophages in the stroma and an infiltrative growth, limited, however, to the liver parenchyma and the intestinal muscular wall of the tumor described here. In our case, moreover, the neoplastic lobules also compressed the hepatic parenchyma, causing atrophy. The other seminomas described in fishes differed from our case in their histological features. The 2 spermatocytic seminomas described by Nigrelli \& Jakowska (1953) and Masahito et al. (1984) were characterized by neoplastic spermatocytes in various stages of maturation, maintaining the normal spermatogenetic stages, while the seminoma described here showed 
undifferentiated neoplastic cells consistent with immature neoplastic elements, typical of classical seminoma and not of the spermatocytic type. The seminoma described by Hubbard \& Fletcher (1985) consisted of well-differentiated populations of large neoplastic cells with a high mitotic rate and not remarkable inflammation and necrosis. In our seminoma, neoplastic cells were undifferentiated, showing rare mitotic figures, large necrotic areas, and scattered clusters of lymphocytes and melanomacrophages in the stroma. Finally, the seminoma described by Palikova et al. (2007) displayed poorly differentiated neoplastic germ cells as in our case; however, the numerous mitotic figures and multinucleated cells described by these authors were not present in our seminoma.

According to the WHO International Histological Classification of the Tumors of the Genital System of Domestic Animals (Kennedy et al. 1998), our seminoma could be classified to exhibit 2 growth patterns: intratubular and diffuse. The evidence of a lobular arrangement of neoplastic cells divided by a stromal component infiltrated by lymphocytes suggested a similarity with the diffuse form. However, the high malignancy of our seminoma and the probable origin of the neoplastic cells from undifferentiated seminal cells led us to define it as a classical type, according to the WHO classification of testicular tumors in humans (Mostofi \& Sesterhenn 1998).

The immunohistochemical phenotypization of the tumor was made for 2 reasons: (1) to verify eventual similarities among mammalian, human and fish gonadal tumors, and (2) to exclude other celomatic neoplasms such as hepatic or intestinal carcinoma and lymphoma. Some immunophenotypical similarities were found with gonadal tumors reported in mammals and humans. Detailed immunohistochemical studies on human and canine germ cell tumors revealed an immunoreactivity of seminomatous germ cells to vimentin, PLAP, and C-KIT, but not to NSE and cytokeratin (Feitz et al. 1987, Foster \& Ladds 2007, Grieco et al. 2007). PLAP, which is produced ectopically by a variety of malignant tumors including human seminoma, was found to be a specific antibody for neoplastic cells of a classical histotype (Lange et al. 1982, Grieco et al. 2007). c-KIT, which is normally expressed by germ cells, has been validated as a marker to distinguish seminoma from Sertoli cell tumors, as it is also expressed by undifferentiated neoplastic seminal cells (Grieco et al. 2009, Yu et al. 2009). A positivity of neoplastic cells to vimentin, PLAP, and c-KIT was detected in the present study and permitted us to classify the seminoma as a classical type. The PAS staining of seminomatous cells was negative, in contrast to data obtained by Grieco et al. (2007).
As to the differential diagnosis with other celomatic neoplasms, intralobular seminomatous cells were constantly negative to cytokeratins AE1/AE3 in the present study, excluding a carcinomatous origin of this tumor. Similarly, all lymphoid and haematopoietic markers (CD3, CD79 $\alpha$, CD45RA) specific for the detection of lymphoma were negative.

Immunohistochemistry has recently found its application in phenotyping fish neoplasms, such as melanoma, schwannoma, or adenocarcinoma, through expression of markers such as S100 protein, calretinin, or cytokeratin (Sakamoto \& White 2002, Marino et al. 2007, Magi et al. 2008, Marino et al. 2008, Dale et al. 2009). The use of mammalian antibodies in fish tissues has some limitations related to their specificity. However, these can be reduced by the application of appropriate positive controls of mammalian and fish tissues together with a negative control that permits demonstration the specificity of reaction.

In conclusion, the findings of the present study permitted the classification of the neoplasm examined as a classical seminoma with a diffuse pattern. Its malignant behavior was supported by the finding of a massive invasion of the intestinal wall and the liver.

Acknowledgements. We thank Dr. Andrea Andreoli for providing anamnestic data and Dr. Angelo Soragni Jr. for revising the English.

\section{LITERATURE CITED}

Blazer VS (2002) Histopathological assessment of gonadal tissue in wild fishes. Fish Physiol Biochem 26:85-101

Budd J, Schroder JD, Dukes KD (1975) Tumors of the yellow perch. In: Ribelin WE, Migaki G (eds) The pathology of fishes. University of Wisconsin Press, Madison, WI, p 895-906

Dale OB, Torud B, Kvellestad A, Koppang HS, Koppang EO (2009) From chronic feed-induced intestinal inflammation to adenocarcinoma with metastases in salmonid fish. Cancer Res 69:4355-4362

> Dickman MD, Steele PO (1986) Gonadal neoplasms in wild carp-goldfish hybrids from the Welland River near Niagara Falls, Canada. Hydrobiologia 134:257-263

Down NE, Leatherland JF (1989) Histopathology of the gonadal neoplasms in cyprinid fish from the lower Great Lakes of North America. J Fish Dis 12:415-437

Feitz WFJ, Debruyne FMJ, Ramaekers FCS (1987) Intermediate filament protein as tissue specific markers in normal and neoplastic testicular tissue. Int J Androl 10:51-56

Foster RA, Ladds PW (2007) Male genital system. In: Maxie MG (ed) Jubb, Kennedy and Palmer's pathology of domestic animals, 5th edn, Vol 3. Saunders-Elsevier, Philadelphia, PA, p 556-619

> Granado-Lorencio C, Garcia-Novo F, Lopez-Campos J (1987) Testicular tumors in carp-funa hybrid: annual cycle and effect on a wild population. J Wildl Dis 23:422-427

> Grieco V, Riccardi E, Rondena M, Ciampi V, Finazzi M (2007) Classical and spermatocytic seminoma in the dog: histochemical and immunohistochemical findings. J Comp Pathol 137:41-46 
Grieco V, Banco B, Giudice C, Mosca F, Finazzi M (2009) Immunohistochemical expression of the KIT protein (CD117) in normal and neoplastic canine testes. J Comp Pathol

Groff JM (2004) Neoplasia in fishes. Vet Clin North Am Exot Anim Pract 7:705-756

- Hawkins WE, Fournie JW, Ishikawa T, Walker WW (1996) Germ cell neoplasms in Japanese medaka. J Aquat Anim Health 8:120-129

Herman RL, Landolt M (1975) A testicular leiomyoma in a largemouth bass, Micropterus salmoides. J Wildl Dis 11: 128-129

Hoole D, Bucke D, Burgess P, Wellby I (2001) Diseases of carp and other cyprinid fishes. Fishing News Books, Blackwell Science, Oxford, p 21-42

$>$ Hubbard GB, Fletcher KC (1985) A seminoma and a leiomyosarcoma in an albino African lungfish (Protopterus dolloi). J Wildl Dis 21:72-74

Ishikawa T, Takayama S (1977) Ovarian neoplasia in ornamental hybrid carp (Nishikigoi) in Japan. Ann NY Acad Sci 298:330-341

Kennedy PC, Cullen JM, Edwards JF, Goldschmidt $\mathrm{MH}$, Larsen S, Munson L, Nielsen S (1998) Histological classifications of tumors of the genital system of domestic animals. In: Schulman FY (ed) World Health Organisation international histological classification of tumors of domestic animals, 2nd series, Vol 4. Armed Forces Institute of Pathology, Washington, DC, p 17-18

Lange PH, Millan JL, Stigbrand T, Vessella RL, Ruoslahti E, Fishman WH (1982) Placental alkaline phosphatase as a tumor marker for seminoma. Cancer Res 42:3244-3247

Leatherland JF, Sonstegard RA (1978) Structure of normal testis and testicular tumors in cyprinids from Lake Ontario. Cancer Res 38:3164-3173

Magi GE, Di Cicco E, Rossi G (2008) Spontaneous intestinal adenocarcinoma in a blue gularis Fundulopanchax sjostedti: an immunohistochemical study. Fish Pathol 43: $128-131$

Marino F, Germanà A, Bambir S, Helgason S, De Vico G, Macrì B (2007) Calretinin and S-100 expression in gold-

Editorial responsibility: Thomas Lang,

Cuxhaven, Germany fish, Carassius auratus (L.), schwannoma. J Fish Dis 30: 251-253

Marino F, Germanà A, Panebianco A (2008) A case of schwannoma in farmed seabream Sparus aurata. Dis Aquat Org 82:249-252

- Masahito P, Ishikawa T, Takayama S (1984) Spontaneous spermatocytic seminoma in African lungfish, Protopterus aethiopicus Heckel. J Fish Dis 7:169-172

Mostofi FK, Sesterhenn IA (1998) Histological typing of testis tumors. In: Schulman FY (ed) World Health Organisation international histological classification of tumors, 2nd edn. World Health Organisation, Geneva

Nigrelli RF, Jakowska S (1953) Spontaneous neoplasms in fishes, Vol 7. A spermatocytoma and renal melanoma in an African lungfish, Protopterus anneetens (Owen). Zoologica 38:109-112

Palikova M, Navratil S, Svobodova Z, Tichy L, Recek L, Pikula $\mathrm{J}$ (2007) Skin and gonadal tumours in a barbel (Barbus barbus) - a case report. Bull Eur Assoc Fish Pathol 27: $236-238$

Sakamoto K, White MR (2002) Dermal melanoma with schwannoma-like differentiation in a brown bullhead catfish (Ictalurus nebulosus). J Vet Diagn Invest 14:247-250

Smolowitz R, Hanley J, Richmond H (2002) A three-year retrospective study of abdominal tumors in zebrafish maintained in an aquatic laboratory animal facility. Biol Bull 203:265-266

Sonstegard RA (1977) Environmental carcinogenesis studies in fishes of the Great Lakes of North America. Ann N Y Acad Sci 298:261-269

Spitsbergen JM, Kent ML (2003) The state of the art of the zebrafish model for toxicology and toxicologic pathology research-advantages and current limitations. Toxicol Pathol 31:62-87

Weisse C, Weber SE, Matzkin Z, Klide A (2002) Surgical removal of a seminoma from a black sea bass. J Am Vet Med Assoc 221:280-283

> Yu CH, Hwang DN, Yhee JY, Kim JH and others (2009) Comparative immunohistochemical characterization of canine seminomas and Sertoli cell tumors. J Vet Sci 10:1-7

Submitted: December 6, 2009; Accepted: August 2, 2010

Proofs received from author(s): September 29, 2010 